\title{
Erratum to: Time-resolved analysis of the emission of sidestream smoke (SSS) from cigarettes during smoking by photo ionisation/time-of-flight mass spectrometry (PI-TOFMS): towards a better description of environmental tobacco smoke
}

\author{
T. Streibel • S. Mitschke • T. Adam • R. Zimmermann
}

Received: 2 April 2013 / Accepted: 2 April 2013 /Published online: 25 April 2013

(C) Springer-Verlag Berlin Heidelberg 2013

Erratum to: Analytical and Bioanalytical Chemistry

DOI 10.1007/s00216-013-6739-y

We should like to call your attention to the fact that unfortunately following paragraph was missing in the published article:

The authors thank for support by the "Institute for Science and Health" Foundation, St. Louis, Missouri, USA.

Furthermore the notice of the "present address" (3rd address) of author T. Adam unfortunately was added by mistake and shall be deleted.

The online version of the original article can be found at http://dx.doi.org/ 10.1007/s00216-013-6739-y.

T. Streibel $\cdot$ R. Zimmermann $(\bowtie)$

Joint Mass Spectrometry Centre, Chair of Analytical Chemistry,

Institute of Chemistry, University of Rostock,

18059 Rostock, Germany

e-mail: ralf.zimmermann@uni-rostock.de

T. Streibel $\cdot$ S. Mitschke $\cdot$ T. Adam $\cdot$ R. Zimmermann Joint Mass Spectrometry Centre, Cooperation Group of

Comprehensive Molecular Analytics (CMA), Helmholtz Zentrum

München-German Research Centre for Environmental Health,

85764 Neuherberg, Germany 